\title{
Public deliberation and private choice in genetics and reproduction
}

Michael Parker Ethox, University of Oxford

\begin{abstract}
The development of human genetics raises a wide range of important ethical questions for us all. The interpersonal dimension of genetic information in particular means that genetics also poses important challenges to the idea of patient-centredness and autonomy in medicine. How ought practical ethical decisions about the new genetics be made given that we appear, moreover, no longer to be able to appeal to unquestioned traditions and widely shared communitarian values? This paper argues that any coherent ethical approach to these questions must be able both to uphold the moral status of the individual and at the same time recognise the communitarian, interpersonal dimensions both of the world in which we live and of personal autonomy itself. The paper then goes on to propose an approach to the resolution of the ethical questions raised by the use of the new genetics in reproductive choice through the development of a coherent and principled process of public reason and justification oriented towards the support and development of personal autonomy.

(Fournal of Medical Ethics 2000;26:160-165)
\end{abstract}

Keywords: Deliberation, autonomy; genetics; reproduction; ethics

The continuing development of human genetics raises a wide variety of important ethical questions for us all, whether as health care professionals, patients, members of families or as individuals. A British Medical Association publication recently described human genetics as:

"a science characterised by rapid and spectacular advances in knowledge. The advances affect not only individual patients, but potentially society at large. Genetics opens possibilities to influence the composition of future generations and the sort of people brought into the world. It raises questions about human identity and free will. Speculation and research about how genes might predispose an individual to develop certain characteristics have long gone beyond the medical preoccupation with health and disease. The intriguing prospect of the heredity of character and behaviour such as criminality is increasingly debated. Human cloning or the possibility of parents selecting the intelligence quotient or other traits of their children appear to bring to life the cliché of 'man playing God'."1

Many of the ethical questions raised by genetics are not new but are given a new, more urgent, intensity by its development. One of the places in which this occurs is in discussion of the responsibilities we have to those to whom we are related. Genetics raises difficult questions both in relation to ourselves and to those around us: to our patients, our families and communities, to other, more distant people, to future generations, and to the non-human world. An example of this which seems certain to be of increasing importance in the future is the question of the use of genetics in reproductive choice, as described in the quotation above. The need to make decisions about public policy in this area combined with the interpersonal dimension of genetic information means that genetics also raises important questions about the relationship between the public and the private in ethics. When, for example, are my reproductive choices, if ever, a matter for me and my family alone, to be made in the privacy of our own home, and when are they, again if ever, a matter for public decision making? In some ways genetics, particularly when combined with new reproductive technology, seems to bring the private into the public arena. ${ }^{2}$

The challenge posed by genetics is further intensified by the fact that despite widespread agreement about the problematic nature of the new genetics, there is little consensus about the grounds upon which the ethical questions it raises should be addressed. To a certain degree, this is a reflection of a broader sense in which we live in a world that at the level of morality is deeply fragmented. It is something of a truism to say that:

"Under modern conditions of life none of the various rival traditions can claim prima facie general validity any longer. Even in answering questions of direct practical relevance, convincing 
reasons can no longer appeal to the authority of unquestioned traditions."

How then, given this apparent lack of consensus and, given that the development and use of the new genetics has implications and effects that range from those affecting families and individuals to those of global proportions, and raises important questions about the relation between the public and the private, are we to go about making ethical decisions about its future development and use?

\section{Patient-centred medicine in the community}

It is common in the context of modern "patientcentred" medicine, to argue that at the heart of any attempt to identify an ethical approach to medicine and to medical research must lie a commitment to the belief that, at least prima facie, people ought to be able to decide for themselves about the kinds of treatments they wish to receive and the information they wish to divulge, or to have divulged about them by health care professionals. It is accepted that this ought not always to be the case, that there will be times when a patient is not competent to make such choices, and circumstances in which the competent autonomous choices of individuals will conflict either with the choices of others or with some perception of their best interests. Nevertheless ethical medicine requires us to take seriously the choices, wishes and desires of the patients we treat. This is often expressed as a requirement that practitioners and researchers respect the "principle of autonomy". ${ }^{4}$

However, this emphasis on autonomy and patient-choice in medicine has, in recent years, been subjected to a certain amount of criticism, both by feminists ${ }^{5}$ and by those who have come to be known as communitarians, ${ }^{6}$ for being overly "individualistic". Communitarians argue that there is a conflict in health care between the individualistic values that underlie patient-centred medicine and the communitarian values that sustain families and communities. Modern medicine's overriding focus on the benefit of the individual patient, they argue, has led to an unhealthy imbalance between individual and community values. They claim that when faced with conflicting treatment choices practitioners, policy makers and indeed patients themselves often adopt the individualistic values of the medical world, leading them, in their pursuit of individualism to undermine the values that sustain the families, relationships and communities in which they live. ${ }^{7}$
The critics of personal autonomy argue moreover, that individualism fails to recognise that many of the most important ethical questions raised by modern medicine and elsewhere only arise at all because we are located in relationships and families and live in a world with others - a world that cannot be characterised in individual terms. ${ }^{8}$ This means, they argue, that there is an important sense in which the moral questions posed by medicine can only be grasped at all in the light of a sense of our location in a world with others.

If these claims are valid with respect to medicine in general, they will be particularly so in relation to the question of whether patientcentred medicine can provide the basis for answers to the ethical questions raised by genetics. For this is where the tensions between individuals and communities are likely to be at their most intense. If these claims are valid they pose a serious threat to patient-centred approaches to the new genetics. But are they valid?

Whilst each of these claims is important, they do not, as they stand, provide as powerful an argument for the rejection of "patientcentredness" in health care as might at first appear to be the case. There are two quite different types of argument that might be used against the communitarian in this regard. The first of these arguments suggests that the communitarian critique of the "individualism" of patient-centred medicine is based upon mistaken claims about the nature of patient choices and about the values by which they are informed. The second argument suggests that contra the claims of the communitarian, the concept of patient-centred medicine is in its own right deeply communitarian. ${ }^{9}$ If so, and if we are serious about communities and relationships, we ought to place more emphasis on personal autonomy rather than less.

\section{Social dimension}

The communitarian claim that an emphasis on autonomy is necessarily individualistic and anticommunitarian is plainly false. To advocate an approach to ethical decision making based on the choices of individuals does not exclude the possibility that the values and choices of such individuals might have a social dimension. ${ }^{10}$ Even if I am free to choose as an individual on the basis of my own values and desires, my choices may well turn out to be deeply communitarian in orientation. I may decide to spend more time with my family, to work with the homeless, to help the elderly or to donate my kidney to someone who needs it. In making my autonomous choices I may very well seek the opinions and suggestions of others. My choices need not necessarily be either selfish or 
detached. As an individual I might value my relationships with others very much indeed and even see them as a priority. It is not necessarily the case therefore that to call for an emphasis on individual autonomy is to advocate a "socially unencumbered" approach to ethics. ${ }^{8}$ Given the invalidity of this conceptual claim, the validity of the communitarian critique of the individualism of patientcentred medicine ultimately comes down to an empirical claim about the actual choices of real people and there seems little evidence to suggest that we are oblivious to communitarian concerns in our actual decision making. Indeed, the very fact that we express concern about these things shows that we are in fact the holders of highly communitarian values. The implication of this is that private autonomous choices will not necessarily, or even contingently, fail to have a communal or public dimension.

\section{Moral dimension}

However, I believe we can go further than this negative claim, to argue that a genuine commitment to personal autonomy requires us to take human relationships very seriously indeed. For, a moral and political emphasis on the value of autonomous decisions and on the promotion of autonomy, implies a commitment not simply to freedom of choice for individual people but also to particular ways of living and deciding with others. ${ }^{11}$ To emphasise the value of patient choice and autonomy consistently is also to place particular value and emphasis upon certain forms of community and of communal life. To live a life that is truly one's own and genuinely autonomous is necessarily more than simply a matter of making choices on one's own and in one's own interest. We live in a world with other people, in networks of relationships, families and "communities", and this means that to live an autonomous life is necessarily to engage in and to take seriously the social dimensions of, and limitations on, one's choices and actions. There are at least three reasons for this, each of which I shall return to later in this paper. Firstly, we cannot be fully autonomous unless we have some say in the socia world in which we live out our lives. It is only by such engagement that we can shape the world in which our choices occur and are made possible. ${ }^{12}$ Secondly, it is by engaging with those around us and by making such choices that we develop our autonomy. ${ }^{13}$ Personal autonomy is made possible by social interaction and in decision making with others. It is not a skill that can be developed alone. ${ }^{11}$ Thirdly, communitarians are correct, it seems to me, in their claim that the very meaningfulness both of the concept of moral choice and of the moral dimension of the world in which we live out our lives, each of which is crucial to the autonomous life, are made possible by virtue of our location in a social world in which there is the use of moral concepts in moral discussion and argument and the use of reasons to justify moral positions. ${ }^{13}$

What these claims imply, if we accept them, is that a serious adherence to the value of autonomy is in many ways itself a deeply communitarian position to adopt. This is because to argue consistently and seriously for the encouragement and expression of personal autonomy in patientcentred medicine is inevitably to support an enriched view of such autonomy and hence of patient-centredness.

No ethical approach to decision making, however, can rely solely on community-based values. Communitarians have rightly been criticised for their unjustifiably optimistic interpretation of community life and for their reliance on a much greater social coherence and sharing of values than actually exists. ${ }^{14}$ It seems empirically at least to be the case that many paradigmatic communitarian communities, such as the family, are in fact as often sites of conflict, violence and clashes of values as they are of mutual support and shared values. It seems undeniable that communitarians are also at the very least guilty of underplaying the potentially damaging effects of communities and of social pressure upon individuals and minority groups. ${ }^{15}$

\section{Conflicts of values}

Conflicts of values and the existence of disadvantage in real communities are problematic for communitarians because they emphasise that whilst communitarians describe very well the damage that can occur when people attempt to escape, or are excluded from, communities, they are incapable of explaining the damage that is sometimes caused by such communities themselves. Some crucial dimensions of our moral world, notably the need to uphold the rights of individuals (say of the genetically disadvantaged) against the community at large are not consistent with a communitarian framework. Consequently communitarianism also says little for those who feel themselves to be excluded from or at the fringes of communities because it fails to see that the convergence of ideas with those of the community is in itself no guarantee of justice. Ultimately, taken to its logical extreme the communitarian belief that the community, relationships and traditions are the highest goods, is capable of justifying the oppression of minorities (including individuals) by the majority. Developments in testing and screening 
offered by the new genetics offer the potential at least for just this kind of discrimination and this ought to make us particularly wary of the use of overly community-based approaches to decision making in the case of the application or otherwise of the new genetics. Whilst communitarians attack the emphasis on personal autonomy for its inability to recognise the fact that our understanding of moral problems arises out of our shared ways of life with others, communitarianism itself seems to lose sight of what is surely the central achievement of patient-centred medicine, which is the recognition that we need to be able to uphold the rights of individuals. Whilst the communitarian might reply that the good life can only be lived in a community wherein rights and responsibilities cohabit in a state of "healthy balance", ${ }^{16}$ this leaves dangerously open the question of just who is to decide the parameters of such a balance.

\section{Public reason for personal autonomy}

Any consistent approach to the making of ethical decisions in health care must be capable of recognising the moral status of individual people and of their choices. An approach which is serious about autonomy must at the same time be capable of capturing the importance of both the communitarian conditions for the development of personal autonomy and the communitarian dimension of the world in which we live. I want now briefly to sketch out some of the implications of these claims for ethical decision making in health care practice.

In the context of a relatively abstract discussion about the relationship between individuals, relationships and communities in medical ethics, it is sometimes easy to overlook the fact that the individual and the community meet in the everyday relationships between real people. It is here, in the relationships between people, that the community comes to have an effect upon the lives of individuals and also here that individuals come to have an effect upon the communities in which they live. ${ }^{17}$ It follows from this and from the arguments I sketched out earlier in this paper that what is required if we are to make ethical choices about the future of human genetics (or indeed about any other ethically problematic area of health care practice), is a coherent process of public reason and justification oriented towards the support and development of personal autonomy. For it is only within the context of a public process of this kind that it is possible to approach ethical decision making in health care in a way which captures the value of both individuals and communities.

Such an approach, whilst in an important sense communitarian, is able to avoid the usual dangers of communitarianism because it is founded upon, and oriented towards, the development and exercise of personal autonomy. It differs from communitarianism also because the orientation of the process is not towards the support of values that sustain families and communities as such, but towards the development of communal processes and institutions insofar as, and because, these values, families and communities themselves, promote and sustain the personal autonomy and the self-realisation of their members. This has the added advantage of providing room for a critique of those social and communal practices which do not promote or respect personal autonomy (such as infibulation).

A process of this kind, based as it is in a respect for and the promotion of personal autonomy would have to accord with certain principles, the justification of which would lie in the extent to which they too support or contribute to the actual expression and development of such autonomy and the extent to which they frame a process which facilitates such development. What would be the key features of such an approach?

Firstly, it follows from the emphasis on the value of personal autonomy that ethical decisions are best made, and in fact might in some cases only be capable of being made, by those people most likely to be affected by the decision at hand and this is to suggest that such a process would be one adhering to a prima facie principle of respect for "enriched personal autonomy". Secondly, such an approach is also, for the same reason, one which emphasises "participation" and this means that the requirement for decisions to be made by those most likely to be affected will in each case need to be assessed against a responsibility to ensure the participation of all who have a legitimate interest. This is to suggest that in practice decision making will have to take a range of different interdependent forms, the form most appropriate in relation to any particular question being dependent upon the extent of legitimate interest in the question at hand. In the case of issues of widespread public or even global concern such as the genetic modification of crops, the sale of genetically modified foods or the funding of research into the development of new techniques such as reproductive cloning, ${ }^{18}$ for example, the most appropriate deliberative process might be the use of a publicly funded consensus conference or of other deliberative decision making models, such as deliberative opinion polls ${ }^{19}$ or appropriately constituted ethics committees. The principle of respect for "enriched personal autonomy" will mean, however, that in some, perhaps most, instances decision making will devolve to deliberative processes on a smaller scale such as those 
involving practitioners, patients and their families. And, given the underlying commitment of this approach to the development of personal autonomy, it will be perfectly appropriate, in many circumstances, for such deliberation to be the concern of the patient alone. Indeed, given the commitment of this approach to enriched personal autonomy the default position in any decision will be that of the autonomy of the patient. Justification of the expansion of the process, in accordance with the principle of "participation" to include others such as families and communities will depend upon the giving of reasons which cannot reasonably be rejected in a public forum and which are commensurate with respect for personal autonomy.

The balance between the principles of respect for "enriched personal autonomy" and "participation" would inevitably in many cases be problematic, raising, for example, important questions about the relationship between the private and the public in ethical decision making. This can be seen in many ways as an opportunity. For, within this framework the question of the balance between participation and autonomy, the public and the private, in any particular case would itself have to be resolved by appropriate processes of rational and public deliberation oriented towards the encouragement of personal autonomy. Such a process (or processes) would enable us to address many of the most fundamental and difficult questions raised by the new genetics. It may be perfectly reasonable for a community to decide, for example, through an appropriate process of deliberation, that certain reproductive choices are a matter for couples and individuals themselves to make "in private" whilst considering others to be a matter for public consideration and assessment, on the grounds that there is a legitimate public interest in the question at hand (such interest being itself only justifiable in terms of the protection and promotion of the autonomy of its members).

\section{Sex selection}

One possible example in the arena of genetics and reproduction is the question of the right of couples to use genetic techniques to select the sex of their child. ${ }^{20}$ At present such practices are not allowed in the United Kingdom. It is possible to imagine a deliberative process of the kind I have described coming to a different conclusion. It might lead to a decision that sex selection should neither be banned outright nor left to couples to decide for themselves but that permission ought to be dependent on the couple's engagement in a process of public deliberation on the grounds that there is likely to be much at stake in such a decision for people other than those directly involved. It might further be agreed that some reasons for wanting to select the sex of one's child are likely to be acceptable whereas others are not. There might be little resistance to sex selection, for example, in the case of a couple who have a high probability of passing on a harmful sex-linked mutation to their child. At the other end of the spectrum it might be agreed that the selection of the sex of one's child on the basis of the social status of the children of a particular gender should not be allowed. One might imagine this being justified on the grounds that such practices are not compatible with a health care system oriented to the respect for and the development of enriched personal autonomy. Between these extremes there would be many other less clear cut cases in which the giving of convincing reasons in the appropriate forum would be the key to whether or not the practice ought to be allowed. The default position in each case would be respect for the autonomy of the couple and the responsibility for justification would always lie with those who wished to override such autonomy, and not on the couple to justify why they wished to proceed.

\section{Conclusion}

Developments in the new genetics confront us with the most profound and difficult of moral choices. In the not too distant future, it may be appropriate for many of these choices to be considered a matter of personal or local concern. At this stage, however, the future of genetic research and the development of novel treatments and techniques are a matter of public concern and require public deliberation. The global dimension of much of this research and its implications requires that such deliberation ought often to have an international dimension. In a world in which there is much diversity of values and attitudes towards such questions it will inevitably be difficult to find common ground upon which to address them. For this reason I have argued that the resolution of many of the most important ethical questions raised by genetics, and in particular those that arise in relation to families, partnerships, relationships and communities, demands a deliberative and collective process of decision making and I have sketched some of the features of such a process.

I have argued that, despite fundamental differences of values, it is possible, based upon the shared sense we have that any solution to these problems will be one in which the choices, wishes and desires of individual people will be taken seriously, to build an effective and ethical decision making process 
which also takes seriously the communal dimension of such questions. Whilst I have argued that such decision making ought to adhere to these principles and ought in addition to have as its orientation the development of enriched personal autonomy, such an approach will inevitably take a variety of forms and I have also described some of these in the paper. It is not possible, however, to specify these in the abstract because their formation and their acceptance will itself be dependent upon their origin in a deliberative process. Nevertheless, it is clear that such a range will stretch from extensive and wide-scale processes of public deliberation on issues such as the genetic modification of crops and of the development of germline therapies and cloning, to decisions within families and couples and by individuals about certain kinds of genetic tests, reproductive choices and the use of personal genetic information. A deliberative process of the kind I have described offers the possibility of a resolution of some of these questions without itself depending upon an extensive set of deeply shared values, or the imposition of individualistic or communitarian principles. Whilst it does not itself depend upon a non-existent consensus, it offers the possibility of a developing, emerging consensus in a context of diversity - and thereby of addressing the third part of the problem with which I began this paper, notably the existence of a disabling social fragmentation at the moral level. For, the building of a deliberative process such as the one described has the added benefit of leading to the development of shared and relatively stable decision making institutions, perhaps of increasingly shared values and to the development of a deliberative process to which all can sign up, and is in this sense a deeply communitarian project. ${ }^{21}$ It has the value too that it does not have built into it either a requirement, or even an aim, that we should reach general agreement or achieve the end of diversity. Rather, on the contrary, this is a process and an approach that suggests that such diversity of values is to some extent a condition for the possibility of an ethical decision making process. If we are serious about the importance of relationships and about communities in ethical medicine we will take the principle of respect for enriched personal autonomy very seriously indeed.

\section{Acknowledgement}

I would like to acknowledge the support of a University of Melbourne Visiting Research Fellowship in summer 1999 during which I wrote this paper. I would also like to acknowledge the very insightful and useful comments made by Tony Hope, Richard Ashcroft and Julian Savulescu.

Michael Parker, BEd, PhD, is Clinical Ethicist at the Fohn Radcliffe Hospital and Lecturer in Medical Ethics, Ethox, University of Oxford. Ethox is the Oxford Centre for Ethics and Communication in Health Care Practice.

\section{References and notes}

1 British Medical Association. Human Genetics. London: British Medical Association, 1998:1

2 See for example a recent discussion of the consequences of the incorporation of European human rights legislation into UK

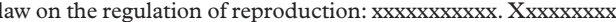
The Guardian $2000 \mathrm{Feb} 14: 1$ and 3. Note in particular the comments both of Ruth Deech, who is the Head of the Human Fertilisation and Embryology Authority and of Lady Warnock, who chaired the 1984 committee of inquiry into human fertilisation and embryology.

3 Habermas J. Fustification and application: remarks on discourse ethics. Oxford: Polity, 1993: 151.

4 Beauchamp T, Childress J. Principles of biomedical ethics [4th ed]. Oxford: Oxford University Press, 1994

5 Frazer E, Lacey N. The politics of community: a feminist critique of the liberal-communitarian debate. Hemel Hemstead:Prentice the liberal-communitarian

6 Lindemann Nelson H, Lindemann Nelson J. The patient in the family. New York: Routledge, 1995.

7 See for example the case study with which Lindemann Nelson $\mathrm{H}$, and Lindemann Nelson J open their book. The patient in the family. New York: Routledge, 1995.

8 Sandel M. Liberalism and the limits of justice. Cambridge: Cambridge University Press, 1982: 179.

9 Parker M. Ethics and community in the health care professions. London: Routledge, 1999.

10 Kymlicka W. Liberalism, community and culture. Oxford: Oxford University Press, 1991.

11 Rousseau JJ. The social contract or principles of political right. London: Penguin Books, 1968: 49-69.

12 Cohen J, Rogers J. Democracy. In: On democracy: toward a transformation of american society. New York: Penguin, 1983

13 MacIntyre A. Dependent rational animals: why human beings need the virtues. London: Duckworth, 1999.

14 Parker M. Communitarianism and its problems. Cogito 1996; 10,3:204-9.

15 The experiences of mental health service users might be seen as a particularly important example of this, for this experience has often been one of exclusion and discrimination and even of violence. See: Lindow V. The exclusion of health service users. In: Parker M. Ethics and community in the health care professions. London: Routledge, 1999: 154-71.

16 Etzioni A. The spirit of community: the reinvention of American society. London: Harper Collins, 1994.

17 Parker M. The growth of understanding. Aldershot: Ashgate, 1995.

18 Special issue of the Bulletin of Medical Ethics which focuses on the proposed revision of the Helsinki Declaration and medical Research in a global context. Bulletin of Medical Ethics 1999;Aug.

19 Fishkin JS. The deliberative poll: bringing deliberation to democracy. In: The voice of the people. Newhaven: Yale University Press, 1995: 161-81.

20 I would like to thank Julian Savulescu and Justin Oakley for suggesting this example.

21 Edgar A. The health service as civil association. In: Parker M. Ethics and community in the health care professions. London: Routledge, 1999:15-46. 